\title{
Effect of sulphadoxine-trimethoprim combination on some pharmacokinetic aspects of sulphadoxine in goats
}

\author{
H.A.H. Zaghloul, A.A.M. El-Gendy ${ }^{*}$, M.A. Tohamy, Abeer M. Radi \\ Pharmacology Department, Faulty of Veterinary Medicine, Beni-Suef University,Beni-Suef,Egypt.
}

\begin{abstract}
Some pharmacokinetic aspects of sulphadoxine alone and sulphadoxine-trimethoprim (TMP) combination were studied in goats following single intravenous (i.v) and intramuscular (i.m) administration of $15 \mathrm{mg} \mathrm{kg}^{-1}$ b.wt. After i.v injection the serum sulphadoxine concentration time course was best described by two compartment-open model with distribution half-lives $(\mathbf{t} 0.5(\alpha))$ 2.48 and $2.31 \mathrm{~h}$., elimination (t0.5( $\beta)$ ) half-lives 23.10 and $24.75 \mathrm{~h}$., total body clearance (CIB) 0.076 and $0.073 \mathrm{~L} \mathrm{~kg}^{-1} \mathrm{~h}^{-1}$ and steady state volume of distribution (Vdss) 368.54 and $411.73 \mathrm{ml} \mathrm{kg}^{-1}$ for sulphadoxine alone and sulphadoxine-trimethoprim combination, respectively. After i.m administration the mean peak serum concentrations (Cmax) 25.69 and $33.31 \mathrm{ug} \mathrm{ml}^{-1}$ were achieved after maximum time (tmax) of 3.09 and $2.79 \mathrm{~h}$. for sulphadoxine alone and sulphadoxinetrimethoprim combination, respectively. The absorption half-lives (t0.5(ab)) were 0.58 and $0.42 \mathrm{~h}$., respectively. It is concluded that a combination of sulphadoxine and TMP can provide a synergistic level for both antimicrobials and thus be a useful combination in the treatment of various goat diseases.
\end{abstract}

Sulphonamides, in combination with a bacterial dihydrofolate reductase inhibitor, develop a highly synergistic antibacterial effect in various bacterial growth systems (Bushby and Hitchings, 1968; Bushby, 1973). Since their introduction in the late $60 \mathrm{~s}$, trimethoprim /sulphonamide, combinations have become very popular for treatment of a variety of infections in man and animals. The advantages of these combinations results in inhibitory effects of trimethoprim and sulphonamide on the two steps of bacterial folic acid synthesis and this leads to an enhanced activity (synergy) compounds when present in combination. This combination also suppresses the emergence of resistance to either compound, at least in vitro (Loscher, 1984). Sulfadoxine is a long-acting sulfonamide, and it inhibits dihydropteroate synthase (DHPS), an enzyme that utilizes para-aminobenzoic acid in the synthesis of dihydropteroic acid. This enzyme is also a component of the folate metabolic pathway and is upstream of DHFR (Dzinjalamala et al., 2005). Trimethoprim (TMP) and sulphonamide combinations have been used in Europe for the treatment of horses since 1970 (Bushby 1980; Alexander and

\footnotetext{
* Corresponding author. Tel.: +20 105380875;

fax: +20822327982 .

E-mail address: elgendyab@yahoo.com

(A.A.M. El-Gendy).
}

Collett, 1975; Becker et al., 1971; Hamza and Rehm 1973). The present study was intended to investigate the pharmacokinetic characteristics of sulphadoxine and trimethoprim (TMP) given in combination to goats. The objective was also to determine whether a combination of sulphadoxine and TMP could provide a synergistic level for both antimicrobials and thus be a useful combination in the management of various goat diseases.

\section{Materials and methods}

Drugs. 1-Sulphadoxine (as pure powder), Intervet Pharmaceutical Company, Nasr City, Egypt. 2-"Sulphadoxine $200 \mathrm{mg}+$ trimethoprim $40 \mathrm{mg}$ ", ratio 5:1 (Borgal ${ }^{\circledR} 24 \%$ solution, Hochest Pharmaceutical Company, Cairo, Egypt).

Animals. Twelve 18-24 month in age clinically healthy, balady female goats weighing $20-25 \mathrm{~kg}$ b.wt. were used. The animals were fed barseem and balanced ration and water ad-libitum. They were kept for one month without any medication before beginning of the study.

Drug administration. The animals were divided into 4 groups (3 goats in each). The first and second groups were given sulphadoxine $15 \mathrm{mg} \mathrm{kg} \mathrm{kg}^{-1}$ b.wt. (single dose) i.v and i.m., respectively. While, the third and fourth groups were given borgal $24 \%$ solution in a dose of $\left(15 \mathrm{mg} \mathrm{kg}^{-1}\right.$ b.wt. sulphadoxine and $3 \mathrm{mg} \mathrm{kg}$ b.wt. trimethoprim) i.v and i.m., 
Table (1): Pharmacokinetic parameters of sulphadoxine alone $\left(15 \mathrm{mg} \mathrm{kg}^{-1}\right.$ b.wt.) and

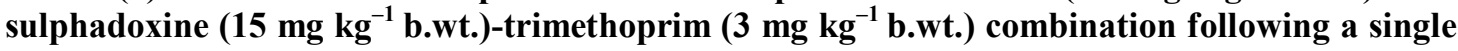
intravenous administration in goats $(n=3)$.

\begin{tabular}{|c|c|c|c|}
\hline \multirow{2}{*}{ Parameter } & \multirow{2}{*}{ Unit } & \multicolumn{2}{|c|}{ Mean \pm SE } \\
\hline & & Sulphadoxine alone & Sulphadoxine-trimethoprim \\
\hline$C p^{0}$ & ug $\mathrm{ml}^{-1}$ & $97.84 \pm 1.87$ & $95.63+2.26$ \\
\hline $\mathbf{A}$ & $\mathrm{ug} \mathrm{ml^{-1 }}$ & $50.58+1.76$ & $59.94+1.42$ \\
\hline$\alpha$ & $\mathrm{h}^{-1}$ & $0.28 \pm 0.006$ & $0.30 \pm 0.006$ \\
\hline$t_{05}(0)$ & h. & $2.48+0.07$ & $2.31+0.05$ \\
\hline B & $\mathrm{ug} \mathrm{ml^{-1 }}$ & $47.26+1.16$ & $35.69+1.54$ \\
\hline $\boldsymbol{\beta}$ & $\mathrm{h}^{-1}$ & $0.03+0.003$ & $0.028+0.007$ \\
\hline$t_{05(\beta)}$ & h. & $23.1+0.35$ & $24.75+1.65$ \\
\hline $\mathbf{k}_{12}$ & $\mathrm{~h}^{-1}$ & $0.16+0.007$ & $0.13+0.009$ \\
\hline $\mathbf{k}_{21}$ & $\mathrm{~h}^{-1}$ & $0.07 \pm 0.006$ & $0.08 \pm 0.002$ \\
\hline $\mathbf{k}_{\mathrm{el}}$ & $\mathrm{h}^{-1}$ & $0.056 \pm 0.004$ & $0.074 \pm 0.006$ \\
\hline Vc & $\mathrm{ml} \mathrm{kg}^{-1}$ & $153.31+2.67$ & $156.85 \pm 3.17$ \\
\hline $\mathbf{V d}_{\mathrm{ss}}$ & $\mathrm{ml} \mathrm{kg}^{-1}$ & $368.54 \pm 2.99$ & $411.73 \pm 3.48$ \\
\hline $\mathrm{Cl}_{\mathrm{B}}$ & $\mathrm{Lkg}^{-1} \mathrm{~h}^{-1}$ & $0.076 \pm 0.004$ & $0.073 \pm 0.008$ \\
\hline $\mathbf{A U C}$ & ug ml$l^{-1} h^{-1}$ & $111.19 \pm 2.26$ & $95.39 \pm 2.48$ \\
\hline
\end{tabular}

respectively. Both sulphadoxine and borgal were administered to each goat by slow i.v injection through the right jugular vein and deep i.m injection in the semitendenous muscle.

Sampling. Blood samples of $10 \mathrm{ml}$ each were collected from the left jugular vein just before dosing and at 5, 10, 15 and 30 min., 1, 2, 4, 6, 8, $12,24,48,72,96$ and $120 \mathrm{~h}$. after drug administration. Blood samples were left to clot for $30 \mathrm{~min}$. then centrifuged at $3000 \mathrm{rpm}$ for 15 min. to obtain clear serum that was kept at $-20^{\circ} \mathrm{C}$ until being assayed.

Each goat was catheterized using folly catheter (No. 12). The bladder was emptied before drug administration. Urine samples were collected prior and at $0.5,1,2,4,6,8,12,24$, 48, 72, 96 and $120 \mathrm{~h}$. after drug administration for both routes. All urine samples were stored at $-20^{\circ} \mathrm{C}$ until used for assessment.

Analytical procedure. The concentration of free and acetylated sulphonamides in serum and urine were estimated spectrophotometrically according to (Bratton and Marshall, 1939). Creatinine concentration in both serum and urine was estimated according to (Bartels and Bohmer, 1971). Creatinine and sulphadoxine clearance were calculated accordind to (Schirmeister et al., 1981; Hayacok, 1981). Sulphadoxine and creatinine clearance ratio was calculated to determine the pathway of sulphadoxine elimination through the kidney.

Pharmacokinetic analysis. The pharmacokinetic parameters were calculated according to (Baggot, 1978). The parameters calculated included $\mathrm{A}$ and o. intercept and slop of the distribution phase), B and $B$ (intercept and slop of the elimination phase). The experimental constants (A, B, œ and B) were used to calculate the actual pharmacokinetic rate constants $\left(\mathrm{K}_{12}\right.$, $\mathrm{K}_{21}$ and $\mathrm{K}_{\mathrm{cl}}$ ) which are associated with the mathematical model. The volume of distribution of the central compartment $\left(\mathrm{V}_{\mathrm{c}}\right)$ was obtained from the equation: $\mathrm{Vc}\left(\mathrm{ml} \mathrm{kg}^{-1}\right)=$ Dose (ug kg$\left.{ }^{1}\right) / \mathrm{C}^{\mathrm{o}}$ ( ug ml $\left.\mathrm{l}^{-1}\right)\left(\mathrm{C}^{\mathrm{o}}\right.$ is the drug concentration at the time of i.v. injection, $\left.\mathrm{C}^{\mathrm{o}}=\mathrm{A} / \mathrm{e}+\mathrm{B} / \mathrm{B}\right)$. Total body clearance $\left(\mathrm{Cl}_{\mathrm{B}}\right)$ expressed in $\mathrm{ml} \mathrm{kg}^{-1}$ $\min ^{-1}$ was calculated as $\left(\mathrm{Cl}_{\mathrm{B}}=\mathrm{K}_{\mathrm{el}} \mathrm{x} \mathrm{Vc}\right)$. Bioavailability \% (F) = (AUCi.m/AUCi.v) $\mathrm{x}$ 100 . AUC is the area under the serum concentration-time curves $\left(\mathrm{AUC}=\mathrm{A}^{\mathrm{c}-1}+\mathrm{B}^{\mathrm{B-1}}\right)$.

The obtained results were statistically analyzed using student " $\mathrm{t} "$ test according to (Snedecor, 1969) and were expressed as means \pm standard error (S.E).

\section{Results}

The mean serum concentration time curves for sulphadoxine alone and sulphadoxine-trimethoprim combination after i.v. and i.m. administration are depicted in (Fig.1, 2) and the pharmacokinetic parameters are presented in (Tables 1,2). The distribution and elimination half-lives for sulphadoxine alone and sulphadoxine-trimethoprim combination were 2.48, 23.10, 2.31 and $24.75 \mathrm{~h}$., respectively. The steady state volumes of distribution $\left(\mathrm{Vd}_{\mathrm{ss}}\right)$ were 368.54 and $411.73 \mathrm{ml} \mathrm{kg}^{-1}$., respectively. As indicated in (Table2), sulphadoxine was rapidly absorbed after i.m. administration with absorption 
Table (2): Pharmacokinetic parameters of sulphadoxine alone $\left(15 \mathrm{mg} \mathrm{kg}{ }^{-1}\right.$ b.wt.) and sulphadoxine (15 mg kg ${ }^{-1}$ b.wt.)-trimethoprim $\left(3 \mathrm{~g} \mathrm{~kg}^{-1}\right.$ b.wt.) combination following a single intramuscular administration in goats $(n=3)$.

\begin{tabular}{cccc}
\hline \multirow{2}{*}{ Parameter } & \multirow{2}{*}{ Unit } & \multicolumn{2}{c}{ Mean $\pm \boldsymbol{S E}$} \\
\cline { 3 - 4 } & $\mathrm{h}^{-1}$ & $1.24 \pm 0.03$ & Sulphadoxine-trimethoprim \\
\hline $\mathbf{k}_{\mathbf{a b}}$ & $\mathrm{h}^{-1}$ & $0.029 \pm 0.001$ & $1.65 \pm 0.06^{*}$ \\
$\mathbf{k}_{\text {el }}$ & $\mathrm{h}$ & $0.58 \pm 0.02$ & $0.04 \pm 0.002^{*}$ \\
$\mathbf{t}_{\mathbf{0 . 5}}(\mathbf{a b})$ & $\mathrm{h}$ & $23.89 \pm 0.95$ & $0.42 \pm 0.03^{*}$ \\
$\mathbf{t}_{\mathbf{0 . 5}(\mathrm{el})}$ & $\mathrm{ug} \mathrm{ml}^{-1} \mathrm{~h}^{-1}$ & $62.68 \pm 2.36$ & $17.325 \pm 1.15^{*}$ \\
$\mathbf{A U C}$ & $\mathrm{ug} \mathrm{ml}^{-1}$ & $25.69 \pm 1.16$ & $92.67 \pm 4.49^{*}$ \\
$\mathbf{C}_{\mathbf{m a x}}$ & $\mathrm{H}$ & $3.09 \pm 0.02$ & $33.31 \pm 1.33^{*}$ \\
$\mathbf{t}_{\mathbf{m a x}}$ & $\mathrm{H}$ & $2.79 \pm 0.07$ \\
\hline
\end{tabular}

(*) Significant at $(\mathrm{P}<0.05)$

Table (3): Urine concentrations of sulphadoxine $\left(\mathrm{ug} \mathrm{ml}^{-1}\right)$ when sulphadoxine alone (15 $\mathrm{mg} \mathrm{kg}^{-1}$ b.wt.) and sulphadoxine ( $15 \mathrm{mg} \mathrm{kg}^{-1}$ b.wt.)-trimethoprim $\left(3 \mathrm{~g} \mathrm{~kg} \mathrm{k}^{-1}\right.$ b.wt.) combination were given in goats by a single intravenous and intramuscular routes $(n=3)$.

\begin{tabular}{|c|c|c|c|c|}
\hline \multirow{3}{*}{ Time (h) } & \multicolumn{4}{|c|}{ Drug concentration $\left(\right.$ ug ml$\left.{ }^{-1}\right)($ Mean $+\mathrm{SE})$} \\
\hline & \multicolumn{2}{|c|}{ i.v } & \multicolumn{2}{|c|}{ i.m } \\
\hline & Drug alone & Combination & Drug alone & Combination \\
\hline 0.5 & $876.61+56.1$ & $1328.0 \pm 115.6$ & $235.65+16.7$ & $325.197 \pm 24.49$ \\
\hline 1 & $1178.2 \pm 73.3$ & $1505.8+96.22$ & $320.48+26.2$ & $465.560 \pm 21.78$ \\
\hline 2 & $947.42 \pm 85.8$ & $875.21 \pm 77.50$ & $636.23 \pm 33.3$ & $763.506 \pm 37.83$ \\
\hline 2 & $749.36 \pm 68.9$ & $621.08+41.76$ & $876.62 \pm 62.9$ & $515.050 \pm 27.88 *$ \\
\hline 6 & $678.67 \pm 58.9$ & $557.16 \pm 35.58$ & $1371.5 \pm 95.4$ & $385.150 \pm 19.43 * *$ \\
\hline 8 & $523.14 \pm 44.3$ & $444.15+33.98$ & $725.07 \pm 34.7$ & $298.120+17.58 * *$ \\
\hline 12 & $296.91 \pm 23.1$ & $250.95 \pm 21.59$ & $617.40 \pm 46.3$ & $195.010 \pm 12.19 *$ \\
\hline 24 & $174.38 \pm 18.5$ & $183.80 \pm 13.85$ & $410.03 \pm 17.5$ & $109.120 \pm 6.45 * *$ \\
\hline 48 & $150.81 \pm 12.9$ & $90.417 \pm 8.426$ & $226.11 \pm 12.3$ & $75.1600+4.618 * *$ \\
\hline 72 & $108.39 \pm 6.70$ & $56.695 \pm 4.7 *$ & $170.36 \pm 7.84$ & $38.0890 \pm 2.732 * *$ \\
\hline 96 & $75.408 \pm 6.85$ & $30.112+2.6 *$ & $90.674 \pm 2.06$ & $15.9730 \pm 0.309 * *$ \\
\hline 120 & $33.5+\overline{2} .84$ & $15.278+1.9 *$ & $45.132+7.63$ & $\overline{\mathrm{ND}}$ \\
\hline
\end{tabular}

$(*)$ Significant at $(\mathrm{P}<0.05) \quad(* *)$ Significant at $(\mathrm{P}<0.01) \quad$ ND: Not detected

Table(4): Sulphadoxine/creatinine clearance ratio when sulphadoxine alone (15 mg kg-1 b.wt.) and sulphadoxine (15 mg kg $\mathrm{b}^{-1}$.wt.)-trimethoprim $\left(3 \mathrm{~g} \mathrm{~kg}^{-1}\right.$ b.wt.) combination were given in goats by a single intravenous and intramuscular routes $(n=3)$.

\begin{tabular}{ccccc}
\hline \multirow{2}{*}{ Time (h) } & \multicolumn{3}{c}{ Drug/creatinine clearance ratio (Mean + SE) } \\
\cline { 2 - 5 } & Drug alone & Combination & Drug alone & Combination \\
\cline { 2 - 5 } & $0.204 \pm 0.014$ & $0.466 \pm 0.025$ & $0.497 \pm 0.019$ & $0.223 \pm 0.0156$ \\
$\mathbf{0 . 5}$ & $0.173 \pm 0.012$ & $0.265 \pm 0.076$ & $0.301 \pm 0.015$ & $0.253 \pm 0.057$ \\
$\mathbf{1}$ & $0.191 \pm 0.082$ & $0.282 \pm 0.011$ & $0.285 \pm 0.050$ & $0.205 \pm 0.09$ \\
$\mathbf{4}$ & $0.260 \pm 0.057$ & $0.258 \pm 0.049$ & $0.358 \pm 0.142$ & $0.094 \pm 0.003$ \\
$\mathbf{6}$ & $0.172 \pm 0.013$ & $0.202 \pm 0.039$ & $0.575 \pm 0.105$ & $0.084 \pm 0.005$ \\
$\mathbf{8}$ & $0.155_{ \pm 0} 0.008$ & $0.161 \pm 0.016$ & $0.386 \pm 0.095$ & $0.073 \pm 0.002$ \\
$\mathbf{1 2}$ & $0.089 \pm 0.007$ & $0.173 \pm 0.052$ & $0.492 \pm 0.117$ & $0.064 \pm 0.0014$ \\
\hline
\end{tabular}


Table(5): Percentage of serum N4-acetylated derivative of sulfadoxine when sulphadoxine

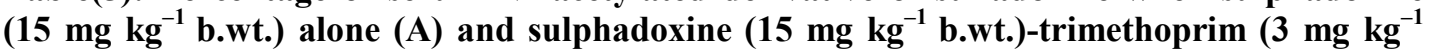
b.wt.) combination (B) were given to goats by a single intravenous (i.v) and intramuscular (i.m) routes $(n=3)$.

\begin{tabular}{|c|c|c|c|c|}
\hline \multirow{3}{*}{ Time (h) } & \multicolumn{4}{|c|}{ Concentration $\left(\right.$ ug ml $\left.^{-1}\right)($ Mean \pm SE) } \\
\hline & \multicolumn{2}{|c|}{ i.v } & \multicolumn{2}{|c|}{ i.m } \\
\hline & $\mathbf{A}$ & $\mathbf{B}$ & $\mathbf{A}$ & $\mathbf{B}$ \\
\hline 0.083 & ND & ND & ND & ND \\
\hline 0.167 & ND & ND & ND & ND \\
\hline 0.25 & ND & $\mathrm{ND}$ & $5.509+0.431$ & $7.32+0.324$ \\
\hline 0.5 & $0.25 \pm 0.013$ & $1.05 \pm 0.025^{* *}$ & $6.311 \pm 0.367$ & $9.48 \pm 0.738$ \\
\hline 1 & $2.23 \pm 0.135$ & $4.647 \pm 0.067 * *$ & $9.45 \pm 0.578$ & $15.1 \overline{2} \pm 1.10$ \\
\hline 2 & $3.339 \pm 0.256$ & $5.233 \pm 0.351 *$ & $11.68+0.897$ & $20.47 \pm 1.32 *$ \\
\hline 2 & $4.595+0.246$ & $6.638 \pm 0.452$ & $13.4 \overline{5}+1.2$ & $28.543+1.39 *$ \\
\hline 6 & $9.423+1.537$ & $11.432 \pm 1.947$ & $17.172 \pm 1.34$ & $36.611 \pm 2.81 *$ \\
\hline 8 & $13.934+1.978$ & $16.46+3.982$ & $20.47+1.65$ & $46.68+2.45 *$ \\
\hline 12 & $35.337 \pm 8.34$ & $38.37 \overline{2}+9.76$ & $36.408+2.312$ & $50.93+2.33 *$ \\
\hline 24 & $45.374+2.28$ & $50.211+3.24$ & $43.621 \pm 1.68$ & $53.76 \pm 1.51 *$ \\
\hline 48 & $50.672+3.93$ & $55.077 \pm 3.75$ & $48.20 \pm 1.23$ & $57.35+1.72 *$ \\
\hline 72 & $38.5 \pm \overline{3} .46$ & $60.669 \pm 4.53$ & $53.024 \pm 2.07$ & $64.7 \pm 1.75^{*}$ \\
\hline 96 & $40.052+2.57$ & $56.859 \pm 3.26$ & $\mathrm{ND}$ & ND \\
\hline 120 & $45.36 \pm \overline{3} .26$ & $50.115 \pm 3.78$ & ND & ND \\
\hline
\end{tabular}

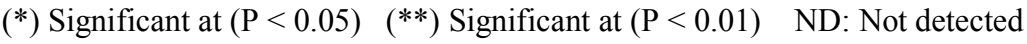

Table(6): Percentage of urine N4-acetylated derivative of sulfadoxine when sulphadoxine (15 mg $\mathrm{kg}^{-1}$ b.wt.) alone (A) and sulphadoxine (15 mg kg-1 b.wt.)-trimethoprim (3 mg kg $\mathrm{g}^{-1}$ b.wt.) combination (B) were given to goats by a single intravenous (i.v) and intramuscular (i.m) routes $(\mathbf{n}=3)$.

\begin{tabular}{ccccc}
\hline \multirow{2}{*}{ Time (h) } & \multicolumn{4}{c}{ Concentration $\left(\mathbf{u g ~ m l}^{-\mathbf{1}}\right)(\mathbf{M e a n} \pm \mathbf{S E})$} \\
\cline { 2 - 5 } & $\mathbf{A}$ & $\mathbf{i . v}$ & $\mathbf{A}$ & $\mathbf{\text { i.m }}$ \\
\cline { 2 - 5 } $\mathbf{0 . 5}$ & $2.5 \pm 0.122$ & $3.5 \pm 0.287^{* *}$ & $7.02 \pm 0.432$ & $10.37 \pm 0.986$ \\
$\mathbf{1}$ & $5.77 \pm 0.351$ & $8.2 \pm 0.445$ & $10.55 \pm 0.851$ & $16.20 \pm 1.24$ \\
$\mathbf{2}$ & $7.46 \pm 0.458$ & $13.55 \pm 0.952^{*}$ & $15.21 \pm 0.736$ & $20.72 \pm 1.07$ \\
$\mathbf{2}$ & $13.46 \pm 1.262$ & $20.325 \pm 1.384$ & $18.76 \pm 0.25$ & $23.73 \pm 1.98$ \\
$\mathbf{6}$ & $18.18 \pm 0.734$ & $27.25 \pm 1.47^{*}$ & $22.32 \pm 1.01$ & $29.19 \pm 1.13$ \\
$\mathbf{8}$ & $22.5 \pm 1.37$ & $34.62 \pm 1.526^{*}$ & $30.97 \pm 1.32$ & $39.33 \pm 1.29^{*}$ \\
$\mathbf{1 2}$ & $38.47 \pm 1.56$ & $43.84 \pm 2.19$ & $39.52 \pm 1.46$ & $45.15 \pm 1.17$ \\
$\mathbf{2 4}$ & $45.804 \pm 1.98$ & $51.43 \pm 1.68$ & $49.34 \pm 1.36$ & $57.42 \pm 1.25^{*}$ \\
$\mathbf{4 8}$ & $50.07 \pm 1.21$ & $58.82 \pm 1.32^{*}$ & $55.80 \pm 1.13$ & $63.83 \pm 1.36^{*}$ \\
$\mathbf{7 2}$ & $53.5 \pm 1.76$ & $64.28 \pm 1.75^{*}$ & $60.15 \pm 2.38$ & $72.75 \pm 1.52^{*}$ \\
$\mathbf{9 6}$ & $56.20 \pm 1.62$ & $65.216 \pm 1.54$ & $\mathrm{ND}$ & $\mathrm{ND}$ \\
$\mathbf{1 2 0}$ & $58.33 \pm 2.83$ & $59.50 \pm 3.27$ & $\mathrm{ND}$ & $\mathrm{ND}$ \\
\hline
\end{tabular}

$(*)$ Significant at $(\mathrm{P}<0.05) \quad(* *)$ Significant at $(\mathrm{P}<0.01) \quad$ ND: Not detected 


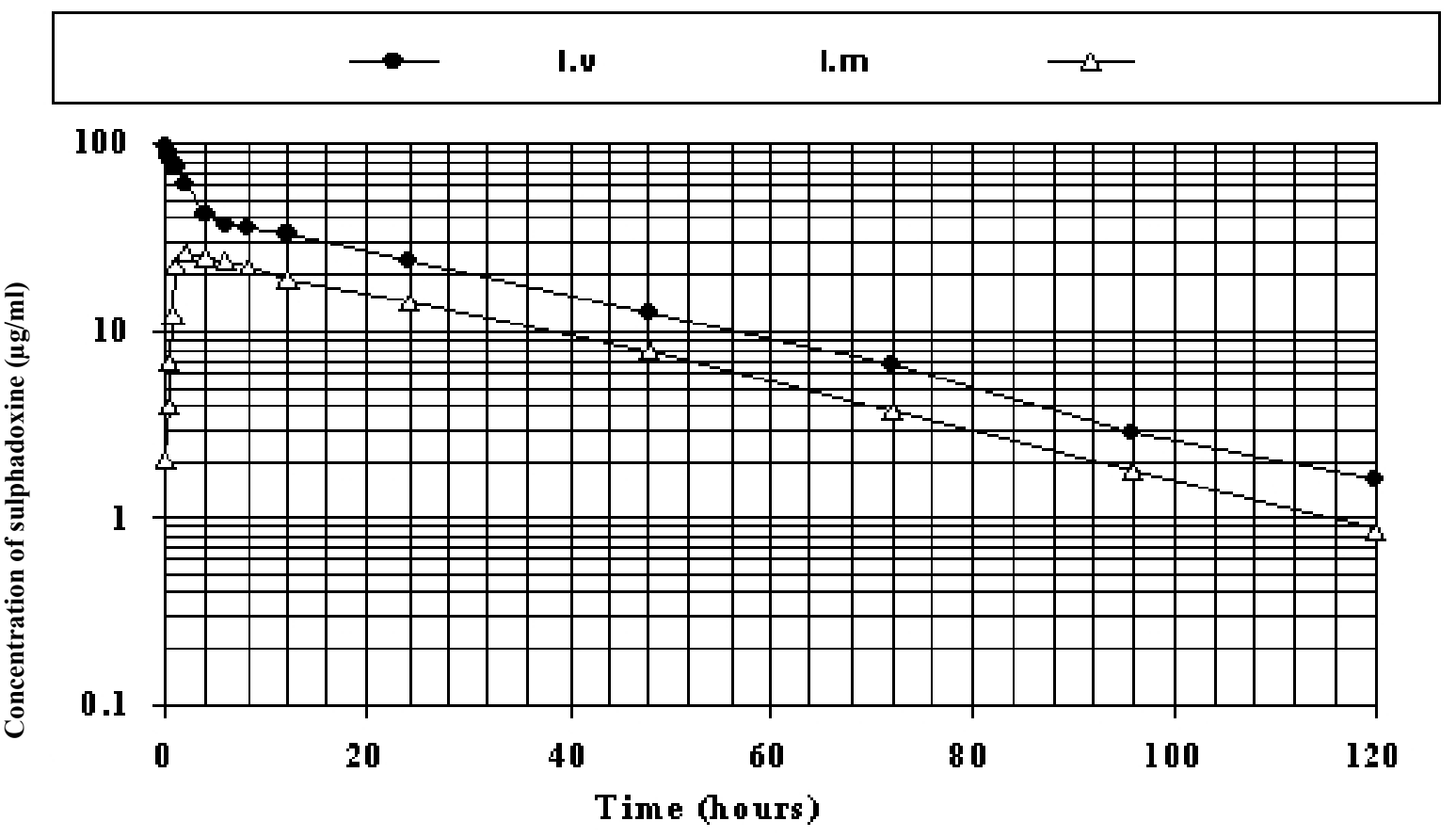

Fig. (1): Semilogarithmic graph depicting the time-concentration of sulphadoxine in serum of goats after single intravenous (i.v) and intramuscular (i.m) injection of $15 \mathrm{mg} / \mathrm{kg} . \mathrm{b} . \mathrm{wt}$.

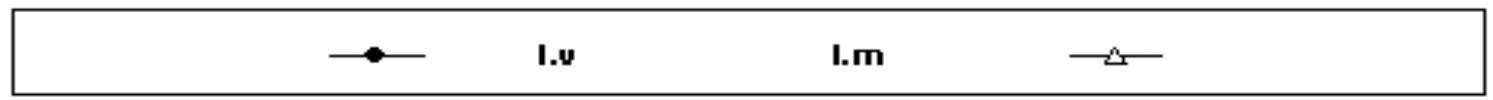

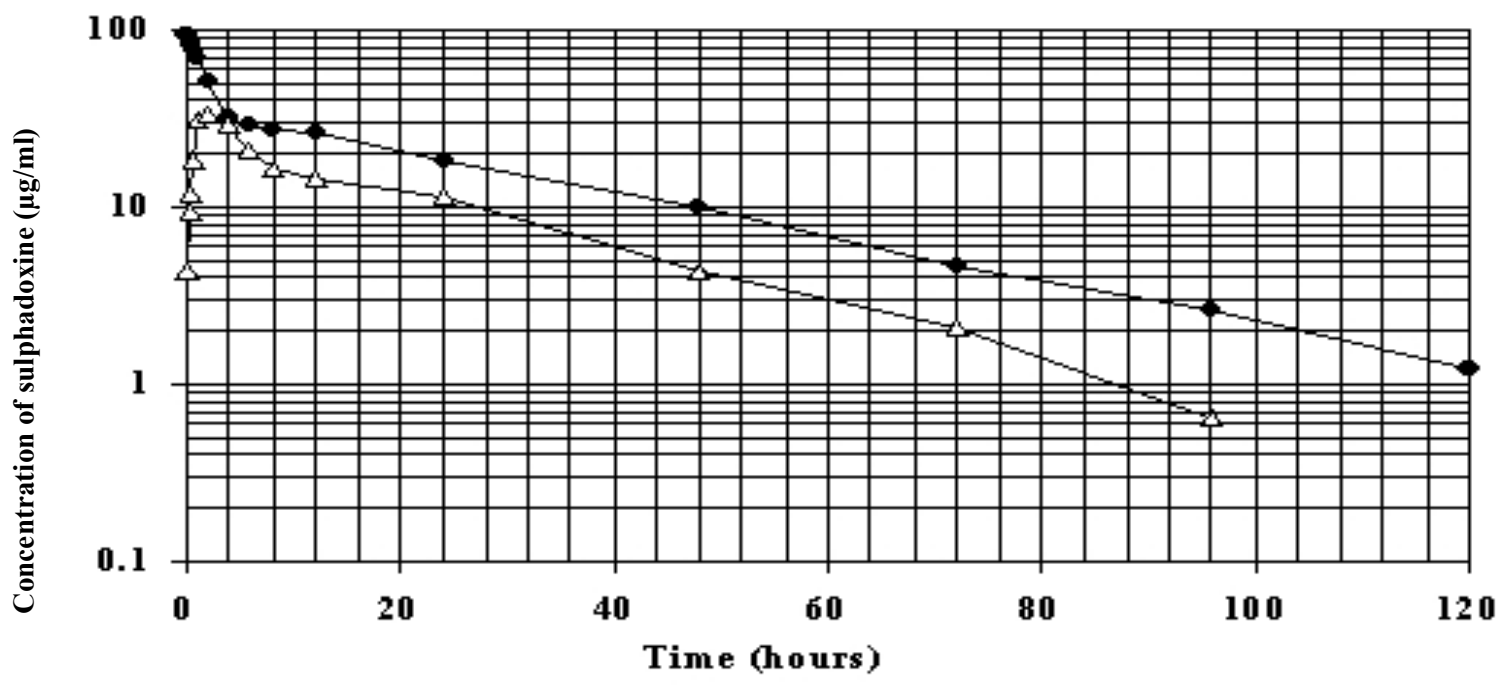

Fig. (2): Semilogarithmic plot depicting the time-concentration of sulphadoxine in sulphadoxine (15 mg/kg.b.wt.)-trimethoprim $(3 \mathrm{mg} / \mathrm{kg} \mathrm{b.wt)}$ combination in goat's serum after single intravenous (i.v)and intramuscular (i.m) injection. 
with absorption half life ( $\left.\mathrm{t}_{0.5(\mathrm{ab})}\right) 0.58$ and $0.42 \mathrm{~h}$. for the drug alone and in combination with trimethoprim. The peak serum concentrations $\left(\mathrm{C}_{\max }\right) 25.69$ and $33.31 \mu \mathrm{g} \mathrm{ml}^{-1}$ were achieved after maximum time $\left(\mathrm{t}_{\max }\right) 3.09$ and $2.79 \mathrm{~h}$. postadministration, respectively. Sulphadoxine was found to be excreted at higher concentrations in urine of goats than those detected in serum following both i.v. and i.m. routes (Table 3 ). The ratios between sulphadoxine clearance from blood of goats to creatinine clearance are presented in (Table 4). The ratios between sulphadoxine clearance to creatinine clearance were less than one. The percentage of N4acetylated derivatives of sulphadoxine was higher in urine than in serum and also higher in sulphadoxine-trimethoprim combination than in sulphadoxine alone after both i.v and i.m administration as recorded in (Tables 5, 6).

\section{Discussion}

Following i.v injection of goats with sulphadoxine alone and sulphadoxine in combination with trimethoprim in a single dose of 15 and $15+3 \mathrm{mg} \mathrm{kg}^{-1}$ b.wt., respectively, the serum concentration time curves were best described by a two compartment-open model. This finding was consistent with result that reported for sulphadoxine in calves (Srivastava et al., 1992; Pashov et al., 1984), but inconsistent with that recorded in horses (Rasmussen et al., 1979) and in dwarf cross kids (Watson et al., 1987).

In case of sulphadoxine-trimethoprim combination, the drug was distributed slightly faster than sulphadoxine alone with $t_{0.5(\alpha)}$ of 2.31 as compared to $2.48 \mathrm{~h}$. This value was higher than that observed in horses $1.33 \mathrm{~h}$. (Rasmussen et al., 1979). This is possibly caused by differences in rates by which the drug can penetrate into the tissues. Differences in kinetic parameters are relatively common and are frequently related to interspecies variation, age, breed, health status of the animals and/or the assay method used (Haddad et al., 1985).

The elimination half-life was not significantly different from that reported with sulphadoxine-trimethoprim combination that was consisted with that reported in swine 9.6 and 10 h., respectively (Lu, 1986). Sulphadoxine was distributed in the central compartment with volume of distribution (Vc) $153.31 \mathrm{ml} \mathrm{kg}^{-1}$ and volume of distribution at steady-state (Vdss) $368.54 \mathrm{ml} \mathrm{kg}^{-1}$. This increase of Vdss over $\mathrm{Vc}$ indicated that the peripheral compartment is the major compartment of sulphadoxine distribution at steady-state. The apparent volume of distribution at steady-state (Vdss) is an accurate indication of the diffusion of the drug into the body tissues (Gilman et al., 1980; Galinsky and Svensson, 1995). In case of sulphadoxine-trimethoprim combination, the drug was distributed in the central compartment with a volume of distribution (Vc) $156.85 \mathrm{ml} \mathrm{kg}^{-}$ ${ }^{1}$ and volume of of distribution at steady-state (Vdss) $411.73 \mathrm{ml} \mathrm{kg}$. When compared with that of sulphadoxine alone, the distribution of combined sulphadoxine with trimethoprim was significantly $(\mathrm{P}<0.01)$ higher than sulphadoxine alone. This variation may be due to increased absorption of the drug when used in combination with trimethoprim than the drug alone.

The volume of distribution at steady-state (Vdss) recorded in this study for sulphadoxine and sulphadoxine-trimethoprim combination were less than unity $\left(<1 \mathrm{~L} \mathrm{~kg}^{-1}\right)$ following i.v dosage in goats indicating moderate or lower distribution of the drug in the extravascular tissues than in blood. This result was similar to that reported by Kaartinen et al. (2000) in preruminant calves and supported by (Baggot, 1978, 1983). The total body clearance of

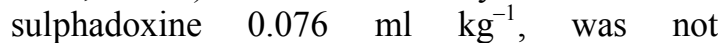
significantly different than that observed in sulphadoxine-trimethoprim combination, which was $0.073 \mathrm{ml} \mathrm{kg}^{-1}$. After i.m injection, the concentration of the drug was higher in case of combination than in sulphadoxine alone in the first $2 \mathrm{~h} . \quad(\mathrm{P}<0.05)$. This indicated that trimethoprim increased absorption of sulphadoxine in the first $2 \mathrm{~h}$. The concentrations of sulphadoxine after $6 \mathrm{~h}$. were gradually decreased in case of combination than that of sulphadoxine alone $(\mathrm{P}<0.05)$, that indicated increased metabolism of sulphadoxine in case of combination. Pharmacokinetic data obtained from administration of sulphadoxine together with trimethoprim were quite different from those obtained after its administration alone. After administration of the drug in combination form, there was a substantial increase in the rate of absorption of sulphadoxine 1.24 to $1.65\left(\mathrm{~h}^{-1}\right)$, with the result that the absorption half-life of sulphadoxine was markedly reduced from 0.58 $\mathrm{h}$. in case of sulphadoxine alone to $0.42 \mathrm{~h}$. in case of combination $(\mathrm{P}<0.05)$. This indicated that the presence of trimethoprim enhance the absorption of sulphadoxine. This agreed with that observed in buffalo calves when given sulphamethoxazole orally alone and with trimethoprim (Jain and Uppal, 1984). The 
maximum concentration (Cmax) for sulphadoxine was $25.69 \mathrm{ug} \mathrm{ml}^{-1}$ in sulphadoxine alone and $33.31 \mathrm{ug} \mathrm{ml}^{-1}$ in combination $(\mathrm{P}<$ 0.05 ) and the time required to achieve this concentration was reduced from 3.09 to $2.79 \mathrm{~h}$., also the area under the plasma concentration curve (AUC) value was higher in combination than when sulphadoxine administered alone $(\mathrm{P}<$ $0.05)$, it was 92.67 and $62.68 \mathrm{ug} \mathrm{ml}^{-1} \mathrm{~h}^{-1}$., respectively. This indicated better absorption of the drug from injection site in presence of trimethoprim. The concentration of the free sulphadoxine in urine increased in case of combination in the first hour (1505.8 ug ml${ }^{-1}$ ) after i.v injection and in the first 2 hours (763.506 ug $\mathrm{ml}^{-1}$ ) after i.m injection than sulphadoxine alone (1178.2 and $636.23 \mathrm{ug} \mathrm{ml}^{-1}$., respectively), then the concentrations gradually decreased after i.v and i.m injection in both cases. The sulphadoxine/creatinine clearance and sulphadoxine-trimethoprim / creatinine clearance ratios ranged from 0.089-0.260, 0.161-0.466, $0.285-0.575$ and $0.064-0.253$ after i.v and i.m injection, respectively. These values indicated that the glomerular filtration is the main route of excretion of both drugs through goat's kidney because the ratios were less than one as reported by Akhtar et al. (1997).

The percentage of N4-acetylated derivatives of sulphadoxine was higher in urine than in serum. This result was similar to that reported for sulphadimethoxine in cattle (Stowe and Sisodia, 1963). Also the percentage of N4acetylated derivatives was increased in sulphadoxine-trimethoprim combination than sulphadoxine alone $(\mathrm{P}<0.05)$. This result is consistent with the finding reported in goats and horses (Jorgensen, et al., 1974; Gelsa, 1979). As reported previously with other sulfonamides, the degree of acetylation increased with the duration of the drug in the body (Stowe et al., 1958). Furthermore, the degree of acetylation in blood and urine increased with time because there was more opportunity for the drug to pass through the liver where acetylation takes place. The increasing in percentage of N4-acetylated derivative in sulfadoxine-trimethoprim combination than sulfadoxine alone indicated that trimethoprim enhance sulfadoxine metabolism which is mainly by acetylation, as mentioned by Jackson et al. (1986) who reported that the main metabolic reaction of sulfadoxine is N4acetylation (30-60\%), glucuronidation also may occur.
After i.m administration, the low concentration of free sulfadoxine and high percentage of its N4-acetylated form indicated that trimethoprim enhanced elimination and/or metabolism of sulfadoxine. This result was similar to that obtained by Jain and Uppal, (1984) after oral administration of sulfamethoxazole in buffalo calves and by Essa, (1988) after oral administration of sulfadimethoxine in goats.

The present study revealed that trimethoprim when given with sulphadoxine, increases its distribution in the body after i.v injection and its absorption from the site of i.m injection. It also enhance the metabolism of sulfadoxine through acetylation and its excretion through kidney. The results also indicated that the glomerular filtration is the main route of excretion of sulfadoxine through the goat's kidney. It could be concluded that sulphadoxinetrimethoprim combination is more effective for treatment of bacterial infection in goats caused by susceptible micro-organisms than sulphadoxine alone.

\section{References}

Akhtar, P.; Nawaz, M.; Iqbal, T. and Nawaz, R. (1997): Renal clearance of creatinine, para-aminohippuric acid, sodium, potassium and chloride during summer and winter season in goats. Veterinapaski Archiv., 67: 267-275.

Alexander, F. and Collett, R.A. (1975): Trimethoprim in the horse. Vet. Res., 7: 203-206.

Baggot, J. D. (1978): Some aspects of clinical pharmacokinetics in veterinary medicine. J. Vet. Pharmacol. Ther., 1: 5-17.

Baggot, J. D. (1983) : Systemic antimicrobial therapy in large animals, in:Bogan, J.A.; Lees, P. and Yoxall, A.T. (Eds). Pharmacological Basis of large Animal Medicine, pp 45-69. (Oxoford, Black Well Scientific Publication).

Bartels, H. and Bohmer, M. (1971): Creatinine-kineticspectrophotometric. Clin. Chim. Acta., 32:81.

Becker, W.; Daerr, H. C. and Borgal, R. (1971): A new chemotherapeutic agent for veterinary medicine. The Blue Book for the Veterinary Profession, 21: 93.

Bratton, R. and Marshall, E. K. (1939): A new coupling component for sulphonamide determination. J. Biol. Chem., 528-537.

Bushby, S. R. M. (1973): Trimethoprim-sulfamethoxazole: in vitro microbiological aspects. J. Infect. Dis., 128: 422462.

Bushby, S. R. M. (1980): Sulfonamide and trimethoprim combinations. Am. J. Vet. Res., 176: 1049-1053.

Bushby, S. R. M. and Hitchings, G. H. (1968): Trimethoprim a sulfonamide potentiator. Br. J. Pharmacol., 33: 72-90.

Dzinjalamala, F. K.; Macheso, A.; Kublin, J. G.; Taylor, T. E.; Barnes, K. I.; Molyneux, M. E.; Plowe, C. V. and Smith, P. J. (2005): Association between the Pharmacokinetics and in vivo therapeutic efficacy of sulfadoxine-pyrimethamine in Malawian Children. Antimicrob Agents Chemother., 49 (9): 3601-3606. 
Essa, M. M (1988): Comparative study on certain pharmacokinetic aspects of some sulfonamides in goats. Thesis of Ph. Fac. Vet. Med., Cairo University.

Galinsky, R. E. and Svensson, C. K. (1995) : Basic pharmacokinetics. In: J.P. Remington (ed.), The science and Practice of Pharmacy, $19^{\text {th }}$ ed, (Mack Publishing Company, Easton, PA), 724-740.

Gelsa, H. (1979): The renal clearance of inulin, creatinine, trimethoprim and sulphadoxine in horses. J. Vet. Pharmacol. Therap., 2(4): 257-264.

Gilman, A. G.; Goodman, L. S. and Gilman, A. (1980): Goodman and Gilman's: The pharmacological basis of therapeutics, $6^{\text {th }}$ ed. P. 21 (New York, MacMillian).

Haddad, N. S.; Pedersoli, W. M.; Ravis, W. R.; Fazeli, M. H. and Carson, R. L. (1985): Combined pharmacokinetics of gentamicin in pony mares after a single intravenous and intramuscular administration. Am. J. Vet. Res., 46: 2004-2007.

Hamza, B. and Rehm, W. F. (1973): Report on the use of a combination of sulphadoxine and trimethoprim in 10,063 cases in veterinary practice. The Blue Book for the Veterinary Profession, 23: 36.

Hayacok, G. B. (1981): Old and new tests for renal function. J. Clin. Path., 34: 1276-1281.

Jackson, J.; Moss. M. and Widdop. B. (1986): Analytical and toxicological data. Clarke's Isolation and Identification of drugs ( $2^{\text {nd }}$ ed. $)$, pp. 978-979.

Jain, S. K. and Uppal, R. P. (1984): Data on the pharmacokinetics of sulphamethoxazole and trimethoprim in buffalo calves. Zbl. Vet. Med. A., 31: 25-30.

Jorgensen, S.; Nielsen, P. and Rasmussen, F. (1974): Renal excretion of N4-acetyl sulphanilamide and N4-acetyl sulphadimidine in goats. Acta Veterinaria Scandinavica, 15: 188-197.

Kaartinen, L.; Gips, M.; Laurila, T.; Härtel, H.; Soback, S. and Pyörälä, S. (2000): Pharmacokinetics of sulphadoxine and trimethoprim and tissue irritation caused by two sulphadoxine - trimethoprim containing products after subcutaneous administration in pre-ruminant calves. Vet. Res., 31: 517-526.

Loscher, W. (1984): Comment on trimetho$\mathrm{prim} / \mathrm{sulfonamide}$ combinations in veterinary medicine. Dtsch. Tierarztl. Wschr., 91: 135-139.

Lu, G. Z. (1986): Pharmacokinetic studies on sulphadoxine and sulphadoxine-trimethoprim combination in swine. Acta Veterinaria et Zootechnica Sinica, 17 (2): 117-122.

Pashov, D.; Mutafchieva, R.; Drumev, D.; Koichev, K. B. and Abramova, N. (1984): Pharmacokinetics, biological availability and tissue residues of a combination of sulphadoxine and trimethoprim injected into calves. Veterinarno Meditsinki Nauki, 21 (4): 84-93.

Rasmussen, F.; Gelsa, H. and Nielsen, P. (1979): Pharmacokinetics of sulphadoxine and trimethoprim in horses, half-life and volume of distribution of sulphadoxine and trimethoprim and cumulative excretion of (C14)trimethoprim. J. Vet. Pharmacol. Therap., 2 (4): 245-255.

Schirmeister, J.; Willmann, H. and Kidfer, H. (1981): Endogenous creatinine in serum and urine. Dtsch. Med. Wschr., 89: 1018.

Snedecor, G.W. (1969): Statistical Methods, $4^{\text {th }}$ ed. The Iowa State Univ. Press. Ames. Iowa, USA. pp. 91.

Srivastava, A. K.; Chaudhary, R. K. and Bal, M. S. (1992): Pharmacokinetics following a single intravenous administration and a dosage regimen for sulphadoxine in buffalo calves (Bubalus Bubalis). Vet. Res. Commun., 16 (3): 215-219.

Stowe, C.; Aronson, A. and Johnson, K. (1958): The pharmacology of sulfabromo-methazine, a new long acting sulfonamide, in cattle. Am. J. Vet. Res., 19:345-353.

Stowe, C. M. and Sisodia, C. S. (1963): The pharmacological properties of sulphadimethoxine in dairy cattle. Am. J. Vet. Res., 24: 525-535.

Watson, A. D. J.; Gogh, H.; Deurzen, E. J. M.; Duin, C. T. M. and Miert, A. S. J. (1987): Pharmacokinetics of three sulphonamides in ruminants and pre-ruminant kids. Res. Vet. Sci. 43 (2): 203-216.

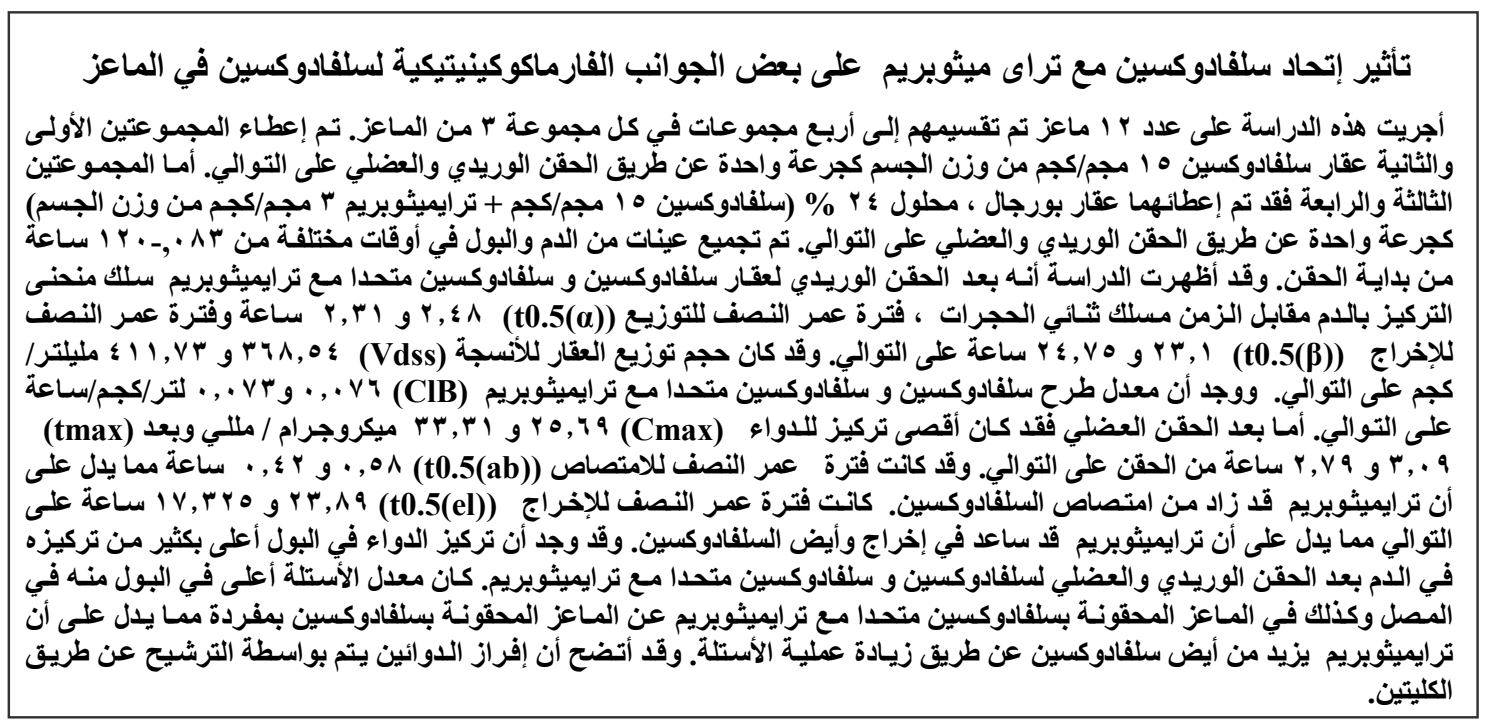

